\title{
Filtros plantados com macrófitas de fluxo vertical aplicados na mineralização e desaguamento de lodo de tanque séptico
}

\author{
Vertical flow constructed wetlands for septic sludge \\ mineralization and dewatering
}

\author{
Carla Suntti \\ Engenheira Ambiental pela Universidade do Contestado (UnC) - campus Caçador. Mestre em Engenharia Ambiental pela \\ Universidade Federal de Santa Catarina (UFSC)
}

Maria Elisa Magri

Engenheira Sanitarista e Ambiental pela UFSC. Mestre em Engenharia Ambiental pela UFSC. Doutoranda em

Engenharia Ambiental pela UFSC. Bolsista CNPq

Luiz Sérgio Philippi

Engenheiro Civil pela UFSC. Doutor em Saneamento Ambiental pela Université de Montpellier I (França) e Professor Titular do

Departamento de Engenharia Sanitária e Ambiental da UFSC

\section{Resumo}

O lodo acumulado no interior de tanques sépticos deve passar por um tratamento antes de sua adequada disposição final, pois apresenta uma fração da matéria orgânica não estabilizada, elevado teor de umidade e organismos patogênicos. Como alternativa para o tratamento do lodo, os filtros plantados com macrófitas são uma tecnologia promissora. Para se avaliar o potencial dos filtros no desaguamento e mineralização do lodo de tanque séptico, foram

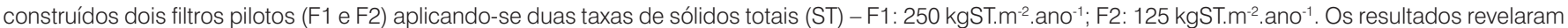
que o F2 apresentou melhor desempenho em relação ao F1 em termos de remoção de sólidos totais (96\%), demanda química de oxigênio (99\%) e nitrogênio amoniacal (72\%). O F2 proporcionou melhor desaguamento, com 67\% de umidade no lodo acumulado no leito e $33 \%$ de sólidos totais.

Palavras-chave: tanque séptico, lodo, filtros plantados com macrófitas, desaguamento.

\section{Abstract}

The accumulated sludge in septic tanks has to be treated before the adequate final disposal, because of its high concentration of non-established organic matter, elevated content of moisture and pathogenic organisms. As an alternative to the treatment of sludge, the vertical flow constructed wetlands are a promising technology. To evaluate the potential of the filters in dewatering and mineralization of septic tank sludge, two pilot-scale constructed wetlands (CW1

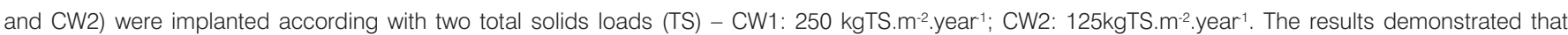
the CW2 had better efficiencies compared with CW1, in terms of total solids (96\%), chemical oxygen demand (99\%) and ammonia (72\%) removal. CW2 also provided a better dewatering, with moisture of $67 \%$ in accumulated sludge and $33 \%$ of total solids.

Keywords: septic tank, sludge, vertical flow constructed wetlands, dewatering. 


\section{Introdução}

O baixo índice de coleta de esgotos no Brasil - 47,9\% em áreas urbanas (SNIS, 2007) - tem impulsionado a utilização de sistemas individuais de tratamento com vistas a proporcionar um destino adequado aos despejos domésticos. Entre os sistemas mais utilizados no Brasil, destacam-se os tanques sépticos, tendo em vista sua utilização por cerca de $22 \%$ da população brasileira (IBGE, 2008). O uso do tanque séptico se destaca por ser uma tecnologia descentralizada, que permite o tratamento dos despejos in loco, não necessitando de grandes redes de coleta para posterior tratamento. Além disso, a elevada aplicabilidade do tanque séptico está associada a fatores como o custo relativamente baixo de construção e a simplicidade operacional do sistema. No entanto, os tanques sépticos requerem manutenção periódica, uma vez que o lodo acumulado no interior dos mesmos precisa ser removido, de forma a não comprometer o funcionamento do sistema e para que o tanque não passe a funcionar apenas como uma caixa de passagem (PHILIPPI, 1993).

Até recentemente, pouca atenção tinha sido dada para o tratamento e disposição final de lodo de sistemas descentralizados. O que ocorre normalmente é que a limpeza de tanques sépticos fica condicionada aos serviços de empresas conhecidas como "desentupidoras" ou "caminhões limpa-fossa". No entanto, essas empresas, em sua grande maioria, não estão licenciadas no órgão ambiental competente e, muitas vezes, não fornecem uma destinação adequada do material coletado nos tanques sépticos. Nos casos em que existe o controle por parte do órgão ambiental, normalmente é exigido que o lodo seja tratado em estações de tratamento específicas para esse efluente, ou que o mesmo seja encaminhado a estações de tratamento de esgoto. Neste caso, é importante a avaliação do impacto do lodo no funcionamento da estação, pois essa situação promove muita variação das cargas orgânicas e inorgânicas no esgoto a ser tratado, o que pode ocasionar problemas no desempenho das estações de tratamento de fluentes (ETE).

Embora o lodo geralmente permaneça dentro do tanque séptico durante o tempo necessário para que se inicie o estágio de degradação, sua disposição final inadequada no meio ambiente pode oferecer problemas de saúde pública e impactos ambientais aos corpos d'água e ao solo. Esses impactos negativos podem ocorrer, pois o lodo possui uma parcela de matéria orgânica não estabilizada (que proporciona geração de odores desagradáveis), apresenta elevada concentração de bactérias e parasitas causadores de doenças, além de possíveis concentrações de metais pesados, conforme os hábitos dos usuários, e o que foi lançado no tanque séptico. O desafio consiste em proporcionar um tratamento adequado para o lodo de tanque séptico em termos econômicos e ecológicos, visando tecnicamente à estabilização e mineralização da matéria orgânica, bem como à inativação dos organismos patogênicos.
O lodo de tanque séptico também apresenta elevado teor de umidade, representado pela quantidade de água presente, a qual deve ser removida para proporcionar um menor volume a ser manipulado e tratado. A redução da umidade do lodo é apresentada em percentual de umidade ou de sólidos totais, enquanto a estabilização e mineralização da matéria orgânica é medida pela concentração de sólidos totais (ST), sólidos totais voláteis (STV), bem como pelo estágio de oxidação dos compostos nitrogenados. Existem diversos sistemas que possibilitam a remoção da umidade do lodo, seja de tanque séptico ou de ETE, por meio do processo de desaguamento, sendo os principais: centrífugas, filtros prensa e adensadores, os quais permitem obter um lodo com percentual de ST entre 30 e $40 \%$ (ANDREOLI; VON SPERLING; FERNANDES, 2001). Como alternativa tecnológica para esses sistemas de desaguamento, pode-se citar os filtros plantados com macrófitas (constructed wetlands). Esses sistemas utilizados amplamente para o tratamento de esgotos domésticos e industriais foram adaptados com a função de desaguamento de lodos, visando melhorar a eficiência dos leitos de secagem (COOPER; WILLOUGHBY; COOPER, 2004). Nesses sistemas ocorre simultaneamente o desaguamento e a mineralização do lodo. O lodo pode permanecer sobre o leito dos filtros plantados em operação contínua por longos períodos, conforme relatado por Koottatep et al. (2002). Os autores estudaram um sistema em escala real que está em operação há 12 anos na Tailândia, sendo que, nesse período, nunca foi realizada a retirada de lodo dos filtros.

Os filtros plantados com macrófitas caracterizam-se como um sistema natural e descentralizado para tratamento de lodos anaeróbios ou aeróbios, com baixo custo de implantação, simplicidade operacional, baixo consumo energético e passíveis de serem implantados nas mais diversas situações - como em pequenas comunidades, áreas rurais, sistemas condominiais e escolas - além de não necessitarem da adição de produtos químicos para se realizar o desaguamento do lodo (KOOTTATEP et al., 2002; NIELSEN; WILLOUGHBY, 2005). Nesses sistemas, as macrófitas apresentam papel fundamental, pois propiciam boas condições para o processo físico de filtração, suas raízes fornecem condições para aderência de micro-organismos, realizam a transferência de oxigênio, possibilitam um aumento na evapotranspiração do lodo e influenciam no processo de secagem e mineralização do mesmo. A ação do vento sob as plantas também permite que seus caules criem espaços tubulares, os quais permitem a manutenção da drenagem do efluente através do leito (BRIX, 1997; HEINSS; KOOTTATEP, 1998; NIELSEN; WILLOUGHBY, 2005).

Esses sistemas, no entanto, apresentam a desvantagem de requererem grandes áreas para implantação, um longo período para adaptação das macrófitas ao leito e à carga de lodo (HEINSS; KOOTTATEP, 1998; UGGETTI et al., 2009). Além disso, até o presente momento, não se tem critérios de dimensionamento padronizados para os filtros plantados com macrófitas para tratamento de lodo. Os filtros 
atualmente implantados são dimensionados de acordo com a taxa de ST, definida como a concentração de ST aplicados no sistema por unidade de área e tempo (UGGETTI et al., 2010).

Embora o tratamento de lodo por filtros plantados seja uma tecnologia bastante utilizada em alguns países da Europa, Ásia e África (DE MAESENNER, 1997; HARDEJ; OZIMEK, 2002; KOOTTATEP et al., 2002; COOPER; WILLOUGHBY; COOPER, 2004; NIELSEN; WILLOUGHBY, 2005; KENGNE et al., 2008; UGGETTI et al., 2009), no Brasil o processo de tratamento com filtros plantados ainda é muito pouco pesquisado e aplicado.

O presente trabalho teve como objetivo avaliar o desempenho de dois filtros plantados com macrófitas de fluxo vertical (F1 e F2) no desaguamento de lodo de tanque séptico, sob a aplicação de duas taxas de ST, visando à determinação de parâmetros de projeto e operacionais para esses sistemas.

\section{Metodologia}

As atividades de pesquisa foram realizadas no Centro de Treinamento (CETRE) da Empresa de Pesquisa Agropecuária e Extensão Rural de Santa Catarina (EPAGRI), em Florianópolis, Santa Catarina. O CETRE possui um sistema de tratamento de esgotos constituído por um tanque séptico e um filtro plantado com macrófitas de fluxo horizontal utilizado como tratamento secundário. $\mathrm{O}$ tanque séptico tem capacidade de $22,6 \mathrm{~m}^{3}$, com $4 \mathrm{~m}$ de diâmetro e 1,8m de altura útil (SUNTTI, 2010). O tanque séptico recebe efluentes da cozinha e dos banheiros do CETRE. Ressalta-se que o tanque séptico está há cerca de dez anos acumulando lodo, não tendo sido efetuada nenhuma limpeza nesse período. Para o desenvolvimento desta pesquisa, foram construídos dois filtros pilotos plantados com macrófitas de fluxo vertical para o tratamento desse lodo. Cada filtro possui $4,3 \mathrm{~m}^{2}$ de área superficial, com 2,60m de comprimento, $1,65 \mathrm{~m}$ de largura e $0,55 \mathrm{~m}$ de borda livre para acúmulo do lodo. Os filtros foram instalados junto ao sistema de tratamento de efluentes do CETRE. Na Figura 1, tem-se uma representação esquemática do funcionamento do sistema de tratamento.

Os dois filtros pilotos são idênticos, com 0,75m de meio filtrante, sendo a camada no fundo preenchida com 0,45 m de brita $\mathrm{n}^{\circ} 2$, a camada imediatamente superior a esta composta por $0,20 \mathrm{~m}$ de brita $\mathrm{n}^{\mathrm{o}}$ $3 / 4$ e a última camada preenchida com $0,10 \mathrm{~m}$ de areia grossa. Ambos os filtros foram plantados com a espécie de macrófita Zizaniopsis bonariensis, com densidade inicial de 15 mudas por $\mathrm{m}^{2}$. Em cada filtro, foi instalado um sistema para coleta do líquido percolado, sendo que nesse sistema foram interligadas tubulações para ventilação natural do leito, tendo-se uma coluna de ventilação por $\mathrm{m}^{2}$ de filtro. Com a finalidade de evitar a interferência da chuva no tratamento e mineralização do lodo nos filtros, os mesmos foram cobertos com uma lona transparente. A Figura 2 apresenta um esquema do filtro plantado

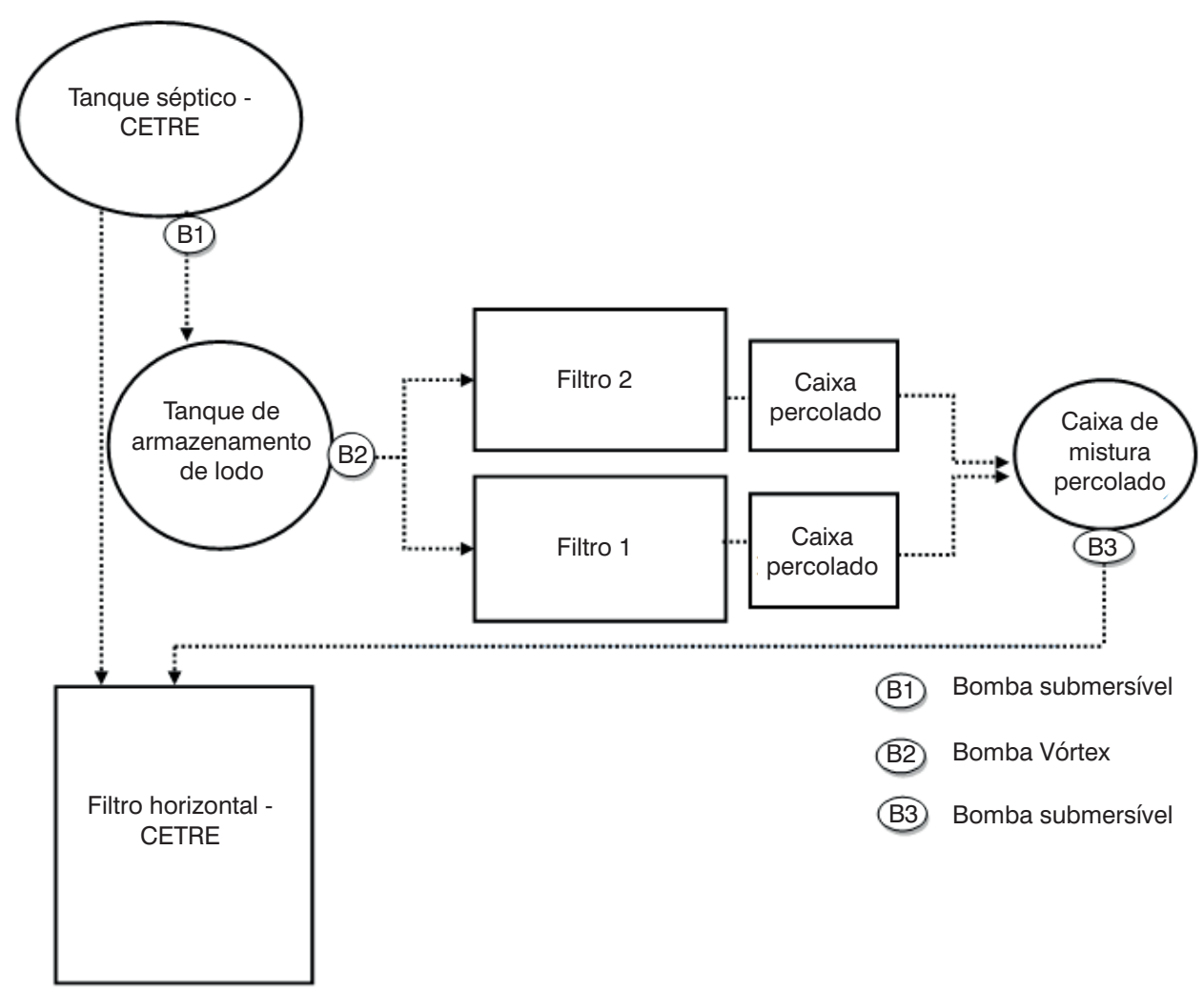

Figura 1 - Fluxograma do funcionamento do sistema experimental. 
para tratamento de lodo e na Figura 3, é apresentada uma foto do sistema estudado.

A operação dos filtros pilotos teve início em março de 2009. Inicialmente, os filtros foram alimentados diariamente com esgoto pré-tratado no tanque séptico para adaptação das macrófitas e formação de biomassa. Após esse período, os filtros foram alimentados com lodo, uma vez por semana, durante 30 dias, com aumento gradativo do volume de lodo aplicado. Essa fase foi adotada com intenção de evitar a morte das plantas devido à maior concentração de sólidos encontrada no lodo do que aquela verificada no esgoto doméstico. Na sequência, os filtros pilotos passaram a receber lodo, uma vez por semana. A operação do sistema foi realizada com fluxo em batelada, com um tempo de detenção hidráulica de seis dias. Cada alimentação em batelada foi denominada de ciclo de operação (período de seis dias para o desaguamento do lodo). Ao término de cada ciclo de operação, a saída dos filtros era aberta para a coleta do líquido percolado

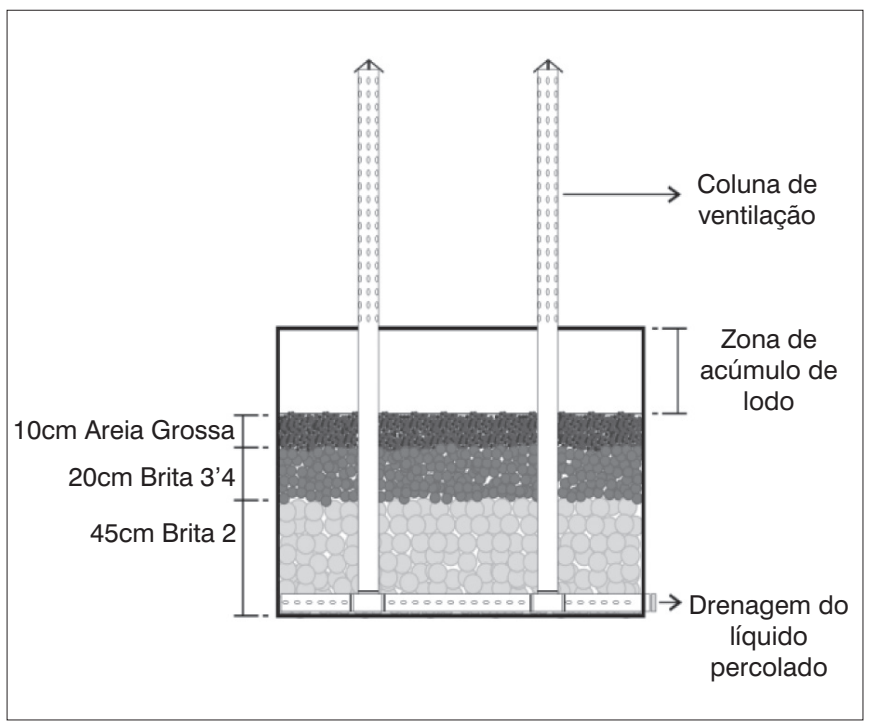

Figura 2 - Representação esquemática do filtro estudado.

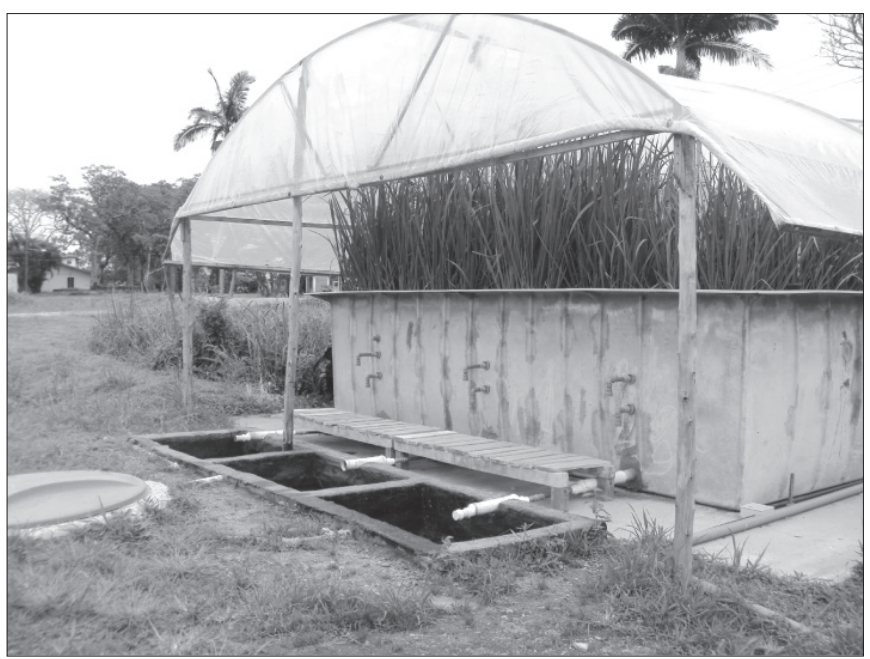

Figura 3 - Foto dos filtros plantados com macrófitas. proveniente do desaguamento. Nessa fase, o lodo era retirado do tanque séptico, com auxílio de uma bomba submersível, e encaminhado para um tanque de armazenamento, do qual era bombeado por meio de uma bomba vórtex para a alimentação dos dois filtros.

Com o objetivo de avaliar o desempenho dos filtros no desaguamento do lodo e indicar parâmetros de projeto, adotaram-se duas taxas de aplicação de ST para alimentação dos filtros: $250 \mathrm{kgST} . \mathrm{m}^{-2}$. ano $^{-1}$ equivalente a $4,8 \mathrm{kgST} \cdot \mathrm{m}^{-2}$.semana ${ }^{-1}$ ou 944L.semana ${ }^{-1}(\mathrm{~F} 1)$ e $125 \mathrm{kgST} \cdot \mathrm{m}^{-2}$.ano ${ }^{-1}$, equivalente a 2,4 $\mathrm{kgST} \cdot \mathrm{m}^{-2} \cdot$ semana $^{-1}$ ou $473 \mathrm{~L}$. semana $^{-1}$ (F2). Essas taxas adotadas estão dentro da faixa avaliada por pesquisadores em outros países, estando consequentemente relacionadas a outras condições ambientais (HEINSS; KOOTTATEP, 1998; KOOTTATEP et al., 2002). Não existem indicações de taxas ou pesquisas relacionadas a esses sistemas no Brasil; portanto, as referências citadas foram utilizadas.

Essa fase teve duração de 126 dias e, durante todo o período de estudo, não foi efetuada a poda das macrófitas nos filtros.

Durante a fase de alimentação dos filtros com lodo, procedeu-se à caracterização do lodo bruto, do líquido percolado gerado e do lodo acumulado no leito a partir de análises físico-químicas distintas. As análises seguiram os procedimentos descritos pelo Standard Methods for Examination of Water and Wastewater (APHA, AWWA, WEF, 1998), exceto para o lodo acumulado nos filtros, o qual foi analisado conforme os procedimentos descritos por Kiehl (1985) para resíduos orgânicos. No lodo bruto e no líquido percolado, foram analisados os seguintes parâmetros: pH, demanda química de oxigênio (DQO), ST, sólidos suspensos (SS), sólidos totais fixos (STF), sólidos totais voláteis (STV) e série nitrogenada (Nitrogênio Total Kjeldahl, amônia, nitrito e nitrato). Para o lodo bruto, além dos parâmetros mencionados, foi avaliada a umidade. O lodo acumulado nos filtros passou a ser analisado a partir do momento em que foi observada quantidade suficiente para coleta das amostras. Os parâmetros analisados foram: altura do lodo no filtro, ST, umidade, porcentagem de matéria volátil e de cinzas. As análises foram realizadas semanalmente, nas dependências da Universidade Federal de Santa Catarina (UFSC), no Laboratório Integrado de Meio Ambiente (LIMA).

Para verificação de diferenças significativas entre as duas taxas aplicadas nos filtros (F1: $250 \mathrm{kgST} . \mathrm{m}^{-2}$.ano ${ }^{-1} ; \mathrm{F} 2$ : $125 \mathrm{kgST} . \mathrm{m}^{-2} . \mathrm{ano}^{-1}$ ) aplicou-se o Teste $t$ de Student, para comparação de grupos independentes, com nível de significância de 5\% $(\alpha=0,05)$. Nesaa etapa, foi avaliada a normalidade dos dados, com auxílio do programa Statistics ${ }^{\circledR} 7.0$.

\section{Resultados e discussão}

\section{Caracterização do lodo}

Ao longo do período estudado (126 dias, correspondente a 16 ciclos de alimentação dos filtros com lodo), observou-se que 
o lodo apresentou elevada concentração de nitrogênio orgânico e matéria orgânica. Pôde-se verificar, ainda, que esse lodo apresentou uma grande variabilidade para todos os parâmetros avaliados, exceto para o $\mathrm{pH}$, o que condiz com a característica de heterogeneidade apontada pela literatura para esse tipo de efluente (Tabela 1)

Em função do elevado tempo de permanência desse lodo dentro do tanque séptico, as concentrações de STV (fração orgânica) foram inferiores (43\%) à concentração dos sólidos fixos (57\% - fração inorgânica), demonstrando que uma expressiva parcela dos sólidos já se encontrava estabilizada. Pela relação entre os STV e sólidos totais ST, é possível conhecer o nível de digestão do lodo, bem como a fração dos sólidos orgânicos. Segundo Andreoli, Von Sperling e Fernandes (2001), em lodos não digeridos, a relação SV/ST é entre 0,75 e 0,80, enquanto que, para lodos digeridos em digestores anaeróbios, esses valores situam-se entre 0,60 e 0,65. Para o lodo avaliado, essa relação apresentou uma média de 0,43, o que, segundo Cofie et al. (2006), é benéfico para o desaguamento do lodo, pois o grau de estabilização (digestão) exerce influência sobre o período de secagem do lodo, sendo que lodos com baixo grau de estabilização apresentam dificuldade no desaguamento.

\section{Remoção da matéria orgânica}

Os filtros apresentaram bom desempenho na remoção da matéria orgânica presente no lodo (Tabela 2), com 99\% de eficiência de remoção de demanda química de oxigênio total (DQOt) para o F2 e 94\% para o F1. Em relação às concentrações de DQOt, verificou-se diferença significativa entre os filtros $(p<0,05)$, sendo que o F2 produziu um efluente menos concentrado do que o F1. Em relação à concentração de ST, novamente o F2 foi o que apresentou um efluente com menor concentração, apresentando uma remoção média de 96\% ( $p<0,05)$. O F2 também foi o que apresentou melhor desempenho quanto à retenção de SS, gerando um efluente com $18 \mathrm{mg} \cdot \mathrm{L}^{-1}$. Esse resultado demonstra que a aplicação da taxa mais baixa $\left(125 \mathrm{kgST} . \mathrm{m}^{-2} \cdot\right.$ ano $\left.^{-1}\right)$ permitiu uma maior eficiência do filtro. Cofie et al. (2006) argumentam que essas excelentes remoções revelam a capacidade do meio filtrante em separar os sólidos presentes no lodo do líquido. Nesse processo, a areia desempenhou um importante papel na retenção dos sólidos presentes no lodo, por meio do processo de filtração.

As eficiências encontradas nesta pesquisa foram semelhantes às obtidas por Paing e Voisin (2005) e Noumsi et al. (2006). Os

Tabela 1 - Caracterização do lodo

\begin{tabular}{|c|c|c|c|c|}
\hline \multirow{3}{*}{ Dados } & \multicolumn{4}{|c|}{ Lodo } \\
\hline & Média & Mínimo & Máximo & Desvio padrão \\
\hline & \multicolumn{4}{|c|}{$\mathrm{n}=20$} \\
\hline $\mathrm{pH}$ & 7,4 & 7,0 & 7,8 & 0,2 \\
\hline $\mathrm{DQOt}\left(\mathrm{mg} \cdot \mathrm{L}^{-1}\right)$ & 14.666 & 2.000 & 27.875 & 9.122 \\
\hline Sólidos totais $\left(\mathrm{mg} \cdot \mathrm{L}^{-1}\right)$ & $18.676,0$ & $3.478,5$ & $36.813,5$ & $10.139,0$ \\
\hline Umidade (\%) & 98,2 & 96,6 & 99,6 & 0,9 \\
\hline Teor de sólidos (\%) & 1,8 & 0,4 & 3,4 & 0,9 \\
\hline Sólidos suspensos (mg. $\left.\mathrm{L}^{-1}\right)$ & $14.645,6$ & $1.690,0$ & $34.054,4$ & $10.233,5$ \\
\hline Sólidos totais voláteis $\left(\mathrm{mg} \cdot \mathrm{L}^{-1}\right)$ & $7.995,5$ & $1.625,5$ & $16.617,0$ & $4.625,3$ \\
\hline Sólidos totais fixos $\left(\mathrm{mg} \cdot \mathrm{L}^{-1}\right)$ & $10.680,6$ & $1.853,0$ & $20.196,5$ & $5.582,6$ \\
\hline Nitrogênio Total Kjeldahl (mg. $\mathrm{L}^{-1}$ ) & 386,0 & 95,2 & 739,2 & 288,9 \\
\hline Nitrogênio amoniacal (mg. $\mathrm{L}^{-1}$ ) & 37,6 & 12,9 & 66,3 & 14,2 \\
\hline Nitrogênio nitrito (mg. $\left.\mathrm{L}^{-1}\right)$ & 0,7 & 0,1 & 2,1 & 0,7 \\
\hline Nitrogênio nitrato $\left(\mathrm{mg}^{-\mathrm{L}^{-1}}\right)$ & 2,5 & 0,8 & 5,5 & 1,4 \\
\hline
\end{tabular}

DQOt: Demanda química de oxigênio total.

Tabela 2 - Concentrações de demanda química de oxigênio (DQOt), sólidos totais (ST) e sólidos suspensos (SS) nos pontos: Iodo bruto e líquido percolado dos filtros F1 e F2 1

\begin{tabular}{|c|c|c|c|c|}
\hline \multirow[t]{2}{*}{ Pontos amostrados } & \multirow{2}{*}{$\begin{array}{c}\text { Taxa }^{2} \\
\left(\mathrm{kgST} \cdot \mathrm{m}^{-2} \cdot \text { ano }^{-1}\right)\end{array}$} & \multicolumn{3}{|c|}{$\begin{array}{c}\left.\text { Parâmetros (mg. } \mathrm{L}^{-1}\right) \\
\text { (Média } \pm \text { desvio padrão) }\end{array}$} \\
\hline & & DQOt & ST & SS \\
\hline Líquido percolado F1 & 250 & $\begin{array}{c}507 \pm 644 a \\
(94 \%)\end{array}$ & $\begin{array}{c}821 \pm 585 a \\
(94 \%)\end{array}$ & $\begin{array}{c}330 \pm 481 a \\
(96 \%)\end{array}$ \\
\hline Líquido percolado F2 & 125 & $\begin{array}{c}85 \pm 40 b \\
(99 \%)\end{array}$ & $\begin{array}{c}472 \pm 68 b \\
(96 \%)\end{array}$ & $\begin{array}{l}18 \pm 11 b \\
(99,9 \%)\end{array}$ \\
\hline \multicolumn{2}{|c|}{ Lodo } & 14.666 & 18.676 & 14.646 \\
\hline
\end{tabular}

${ }^{1}$ Médias seguidas por letras diferentes na coluna e dentro de cada variável diferem entre si pelo teste $t$ a $5 \%$ de significância; ${ }^{2}$ Taxa de aplicação de sólidos totais.

Entre parênteses é mostrada a eficiência de remoção do filtro em relação ao parâmetro em questão. 
primeiros relataram remoções de 99\% de SS e 98,5\% de DQOt, utilizando um filtro plantado para tratamento de lodo de tanque séptico. Os pesquisadores argumentam que esse bom desempenho é devido às degradações biológicas que ocorreram nos filtros, mas, sobretudo, devido aos mecanismos de filtração, que permitiram o acúmulo de sólidos sem comprometer o processo ao longo das aplicações de lodo. Para Noumsi et al. (2006), que avaliaram o potencial do filtro plantado ao tratar lodo coletado de tanques sépticos, banheiros públicos e latrinas, utilizando diferentes taxas de aplicação, obtiveram remoções médias de 99\% de DQOt e 92\% de ST. Os referidos autores destacam que essas remoções indicam que mais de $85 \%$ dos sólidos e matéria orgânica ficaram retidos no sistema.

As taxas de aplicação de ST aplicadas em cada filtro diferiram-se das taxas teóricas previstas no início do projeto, em decorrência da elevada variação na concentração de sólidos presentes no lodo, embora os valores tenham sido próximos às taxas pretendidas (Figuras 4 e 5). As taxas médias aplicadas para os filtros F1 e F2 foram, respectivamente, de 203 e $102 \mathrm{kgST} . \mathrm{m}^{-2}$.ano ${ }^{-1}$.

Os filtros apresentaram bom desempenho na retenção dos sólidos presentes no lodo, mesmo quando as taxas aplicadas foram acima da taxa teórica. A partir das Figuras 4 e 5 , observa-se que os filtros receberam três taxas aplicadas acima da taxa teórica, aos 56, 84 e 98 dias de operação. Pode-se observar ainda que, embora no $56^{\circ}$ dia de operação ( $8^{\circ}$ ciclo) os filtros tenham recebido uma taxa elevada, nos ciclos subsequentes a taxa aplicada foi inferior à taxa prevista, o que não comprometeu o desaguamento do lodo. No $12^{\circ}$ ciclo (84 dias de operação), também não houve comprometimento no processo de desaguamento, pois as taxas anteriores foram abaixo da prevista. No entanto, no $14^{\circ}$ ciclo (aos 98 dias de operação), como os filtros já vinham recebendo uma taxa acima da prevista, foi necessário um período maior para o desaguamento do lodo. Nessa condição, devido às elevadas taxas aplicadas no $14^{\circ}$ ciclo, foram necessários 12 dias para o desaguamento do lodo, ao invés de seis dias, como nos ciclos anteriores.

No decorrer da pesquisa, observou-se que processo de desaguamento do lodo foi influenciado pelos processos de transpiração e evaporação das macrófitas, as quais permitiram uma maior perda de água do leito.

\section{Remoção de nitrogênio}

A maior concentração de nitrogênio total presente no lodo foi na forma orgânica - 348,4 mg.. $\mathrm{L}^{-1}$-, o que corresponde a $90 \%$ do

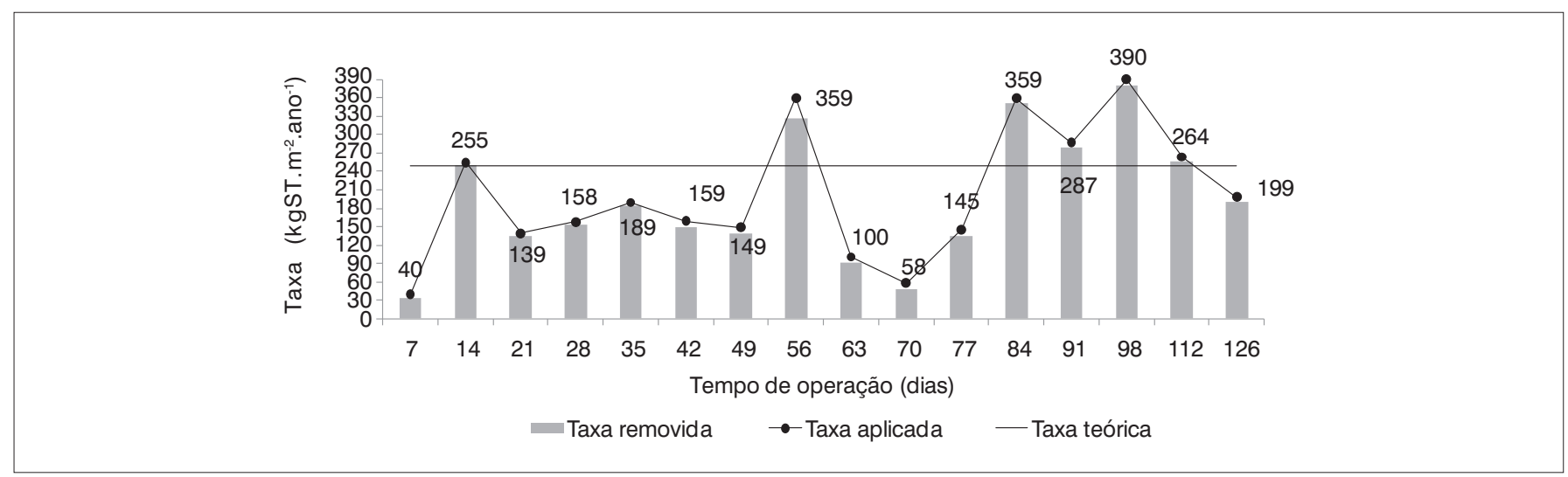

Figura 4 - Taxas aplicadas e removidas no filtro F1 durante os 126 dias de operação.

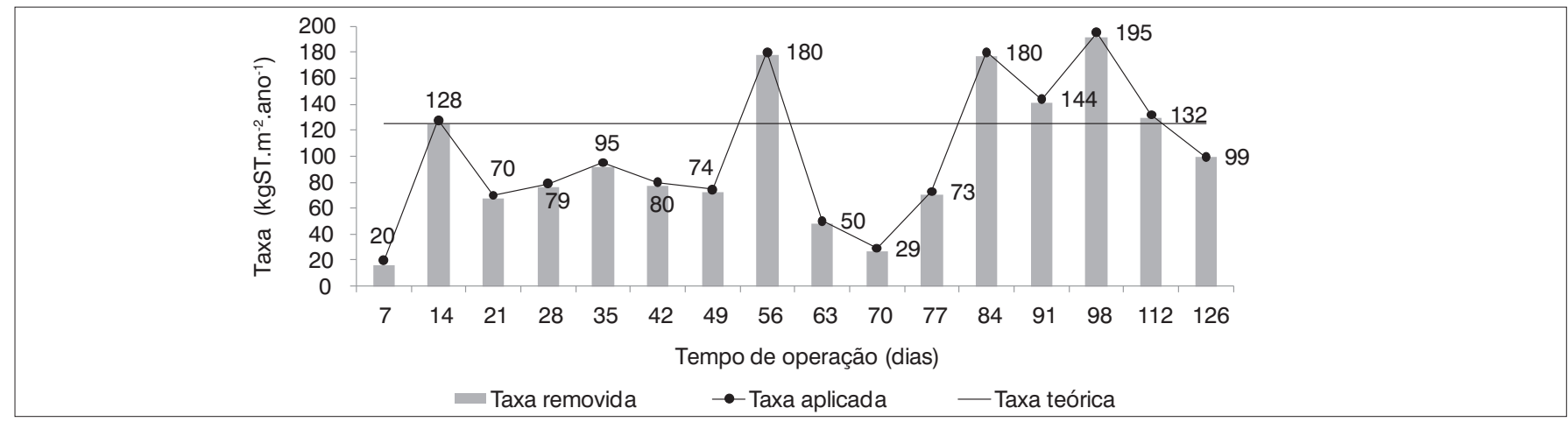

Figura 5 - Taxas aplicadas e removidas no filtro F2 durante os 126 dias de operação. 
nitrogênio total (NT). Considerando o nitrogênio orgânico, verificouse que o F1 apresentou remoções e/ou transformações na ordem de $95 \%$, produzindo um efluente com $16,7 \mathrm{mg} \cdot \mathrm{L}^{-1}$, enquanto que na forma inorgânica a concentração foi de 41,2 mg.L-1. O F2 apresentou $99 \%$ de remoção e/ou transformação do nitrogênio orgânico e concentrações efluentes de $3 \mathrm{mg} \cdot \mathrm{L}^{-1}$, enquanto na forma inorgânica a concentração efluente foi de $70,6 \mathrm{mg} \cdot \mathrm{L}^{-1}$ (Tabela 3).

Com relação às concentrações de amônia, foram obtidas remoções menores - 44\% no F1 e 68\% no F2 -, produzindo efluentes com concentração média de 22,3 e 10,7 mg..-1 , respectivamente.

Parte do nitrogênio orgânico fica retida no leito e lodo acumulado, podendo, mais tarde, ser transformada em amônia pelo processo de mineralização, por meio de hidrólise e degradação bacteriana. A amônia, por sua vez, pode ficar adsorvida no material filtrante e posteriormente ser oxidada a nitrato pelo processo de nitrificação. Com base nessas considerações, constata-se que, dos 90\% de nitrogênio orgânico afluente aos filtros, apenas 5 e 0,9\% saíram no F1 e F2, respectivamente.

No F2, do percentual removido de $\mathrm{NH}_{4}^{+}, 100 \%$ apresentaram nitrificação total, uma vez que a concentração efluente de nitrato $\left(59,3 \mathrm{mg} \cdot \mathrm{L}^{-1}\right)$ foi acima da concentração de amônia de entrada - lodo bruto $\left(37,6 \mathrm{mg} \cdot \mathrm{L}^{-1}\right)$. A concentração efluente no F2 demonstra que o filtro, além de transformar o nitrogênio inorgânico em nitrato, transformou também parte do nitrogênio orgânico. No F1, o mesmo processo não foi verificado, sendo que apenas $42 \%$ da amônia foi oxidada a nitrato, produzindo um efluente com 18,5mg. $\mathrm{L}^{-1}$. Koottatep et al. (2002) verificaram comportamento de remoção de nitrogênio semelhante ao obtido nesta pesquisa. Os autores alcançaram remoções médias na ordem de 93\% para NTK, 80-92\% para nitrogênio amoniacal e elevada produção de nitrato, com concentração efluente variando de 180 a $320 \mathrm{mg} . \mathrm{L}^{-1}$. Os autores destacaram que essa elevada eficiência foi beneficiada pelo sistema de ventilação, o qual permitiu maior entrada de oxigênio no filtro, favorecendo o processo de nitrificação.

O F2, durante o período avaliado (Figura 6), apresentou uma remoção constante da amônia, enquanto que no F1 (Figura 7) o processo de nitrificação somente foi representativo a partir do $91^{\circ}$ dia de operação $(p<0,05)$. Essa diferença está relacionada à carga de nitrogênio aplicada em cada filtro. Platzer (1999) recomenda, para filtros plantados alimentados com esgoto, uma carga máxima de $6,5 \mathrm{gNTK} \cdot \mathrm{m}^{-2} \cdot \mathrm{d}^{-1}$, o equivalente a $45,5 \mathrm{gNTK} \cdot \mathrm{m}^{-2} \cdot$ semana $^{-1}$. No F2, a carga média aplicada foi de $42 \mathrm{gNTK} \cdot \mathrm{m}^{-2}$. semana ${ }^{-1}$, enquanto que o Fl recebeu uma carga média de $85 \mathrm{gNTK} . \mathrm{m}^{-2}$. semana ${ }^{-1}$; isso indica que o F1 recebeu uma carga de nitrogênio total duas vezes acima daquela recomendada pela literatura, sendo este o principal componente responsável pela diferença entre os filtros no processo de nitrificação.

Panuvatvanich, Koottatep e Koné (2009) argumentam que, até o momento, poucos trabalhos têm discutido a transformação de

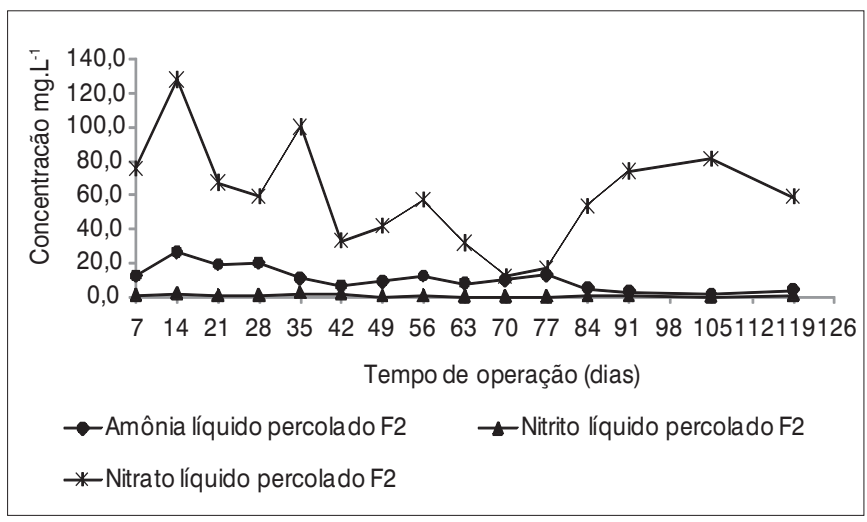

Figura 6 - Transformação do nitrogênio no filtro F2 durante o período avaliado.

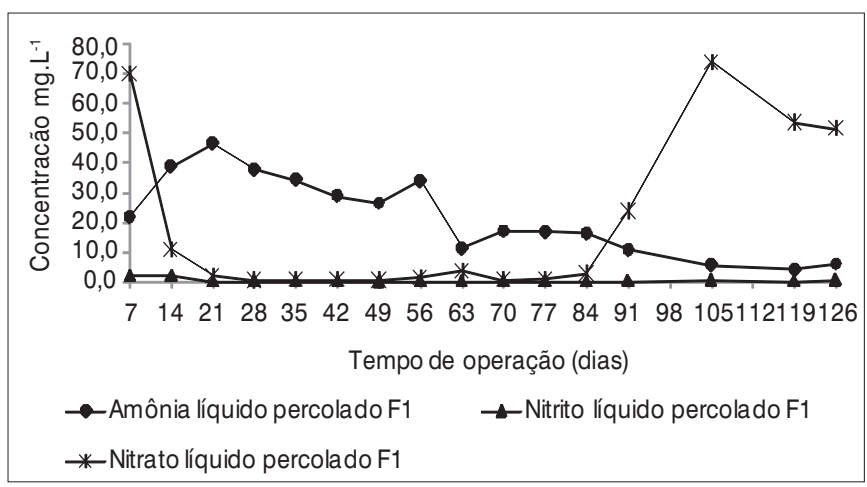

Figura 7 - Transformação do nitrogênio no filtro F1 durante o período avaliado.

Tabela 3 - Caracterização da concentração de nitrogênio no lodo bruto e no líquido percolado nos filtros F1 e F2 ${ }^{1}$

\begin{tabular}{|c|c|c|c|c|c|}
\hline \multirow[t]{2}{*}{ Pontos amostrados } & \multirow{2}{*}{$\begin{array}{c}\operatorname{Taxa}^{2} \\
\left(\mathrm{kgST} \cdot \mathrm{m}^{-2} \cdot \mathrm{ano}^{-1}\right)\end{array}$} & \multicolumn{4}{|c|}{$\begin{array}{c}\text { Parâmetros }\left(\mathrm{mg} \cdot \mathrm{L}^{-1}\right) \\
\left.\text { (Média } \pm \text { desvio padrão }{ }^{1}\right)\end{array}$} \\
\hline & & NTK $^{3}$ & $\mathrm{~N}-\mathrm{NH}_{4}^{+}$ & $\mathrm{N}-\mathrm{NO}_{2}^{-}$ & $\mathrm{N}-\mathrm{NO}_{3}^{-}$ \\
\hline Líquido percolado F1 & 250 & $\begin{array}{c}39,0 \pm 33,3 a \\
(90 \%)\end{array}$ & $\begin{array}{c}22,3 \pm 13,3 a \\
(44 \%)\end{array}$ & $0,4 \pm 0,7$ & $18,5 \pm 27,0 a$ \\
\hline Líquido percolado F2 & 125 & $\begin{array}{c}13,9 \pm 8,0 b \\
(96 \%)\end{array}$ & $\begin{array}{c}10,7 \pm 6,9 b \\
(68 \%)\end{array}$ & $0,6 \pm 0,7$ & $59,3 \pm 30,8 b$ \\
\hline \multicolumn{2}{|c|}{ Lodo bruto } & 386,0 & 37,6 & 0,2 & 2,5 \\
\hline
\end{tabular}

${ }^{1}$ Médias seguidas por letras diferentes na coluna (a,b) e dentro de cada variável diferem entre si pelo teste $t$ a $5 \%$ de significância; ${ }^{2}$ Taxa de aplicação de sólidos totais; ${ }^{3}$ Nitrogênio Total Kjeldahl.

Entre parênteses é mostrada a eficiência de remoção do filtro em relação ao lodo bruto 
nitrogênio nos filtros plantados para tratamento de lodo. Os autores constataram, a partir de um balanço de nitrogênio em filtros plantados, que do nitrogênio total que entrou no sistema, 55\% ficaram retidos no lodo acumulado no filtro, 8-13\% saíram no percolado e as perdas por volatilização e assimilação pelas plantas foram insignificantes $(0,01$ e 0,2\%, respectivamente). Os autores observaram, ainda, que $24-29 \%$ da amônia foram perdidos no sistema devido ao processo de nitrificação e desnitrificação.

\section{Lodo acumulado nos filtros plantados}

Os filtros plantados com macrófitas proporcionaram um acúmulo de lodo sobre o leito, verificando-se, após 126 dias de operação, $13 \mathrm{~cm}$ de lodo acumulado no F1 e $8 \mathrm{~cm}$ no F2. Essa altura variou com o decorrer da operação dos filtros, aumentando lentamente e depois diminuindo, o que foi resultado do processo de desaguamento e mineralização do lodo. Em termos de volume, obtiveram-se 600 e 300L, respectivamente para F1 e F2. Essa diferença era esperada devido ao fato de o F1 ter recebido o dobro da taxa do F2. Destaca-se que, durante todo o período avaliado, não foi verificado crescimento de algas, aparecimento de moscas e surgimento de odor devido ao acúmulo de lodo sobre o leito.

A concentração de matéria orgânica e inorgânica do lodo acumulado, representada pelo teor de ST, foi de $52.089 \mathrm{mg} . \mathrm{L}^{-1}$ no F1 enquanto que no F2, a concentração foi de $68.551 \mathrm{mg} . \mathrm{L}^{-1}$. O lodo acumulado no F2 apresentou um teor de ST mais elevado que o F1 e, consequentemente, menor umidade (Figura 8). No entanto, em relação às características do lodo de alimentação dos sistemas, ambos os filtros proporcionaram um aumento no teor de sólidos, sendo que no lodo acumulado no F1, o teor de sólidos passou de 2 para $24 \%$, enquanto que no lodo acumulado no F2 passou de 2 para $33 \%$. O aumento no teor de sólidos do lodo acumulado nos filtros indica que o processo de desaguamento ocorreu.

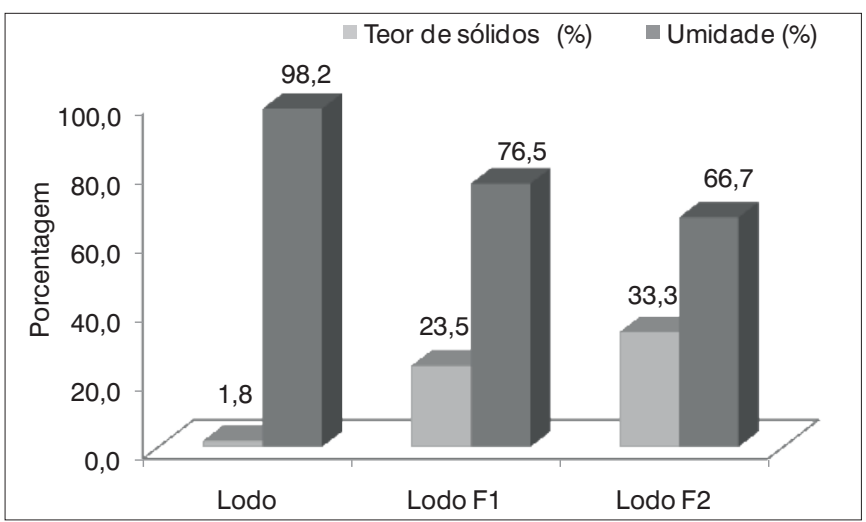

Figura 8 - Teor de sólidos e umidade no lodo de alimentação e no lodo acumulado nos filtros F1 e F2.
Os valores de ST atingidos nesta pesquisa permitiram classificar o lodo acumulado como torta semissólida (ANDREOLI; VON SPERLING; FERNANDES, 2001). As porcentagens de ST obtidas no lodo acumulado, mesmo recebendo lodo fresco semanalmente, foram semelhantes às porcentagens alcançadas por tecnologias convencionais como filtros prensa (30-40\% de ST) e centrífugas (25-35\% de ST) para lodo ativado (ANDREOLI; VON SPERLING; FERNANDES, 2001). Metcalf \& Eddy (2004) relataram 12-30\% de ST em lodo anaeróbio digerido desaguado por filtro prensa. Nos filtros plantados estudados, o percentual de sólidos atingido no lodo acumulado foi obtido com baixo consumo energético, somente com o acionamento das bombas para a alimentação dos sistemas, que era realizada uma vez por semana, sendo que durante todo o período de estudado (126 dias) não foi necessária a retirada do lodo acumulado. Com isso, obteve-se considerável economia em termos de energia, transporte e custos para disposição em aterro, por exemplo. Além disso, não se fez necessária a adição de produtos químicos para propiciar o desaguamento do lodo.

Embora o F1 tenha recebido a maior taxa de ST, o F2 foi o que apresentou maior concentração de sólidos no lodo acumulado e, por consequência, melhor desaguamento (66,7\% de umidade no F2 e $76,5 \%$ de umidade no F1). Essas observações condizem com os resultados obtidos por Stefanakis et al. (2009), os quais ressaltam que o processo de desaguamento foi mais efetivo no filtro que recebeu menos lodo (30kgST.m ${ }^{-2}$.ano ${ }^{-1}$ ), propiciando taxas de evapotranspiração mais elevadas em relação ao filtro que recebeu a taxa maior de lodo $\left(75 \mathrm{kgST} \cdot \mathrm{m}^{-2} \cdot \mathrm{ano}^{-1}\right)$.

\section{Conclusões}

O lodo de tanque séptico avaliado nesta pesquisa apresentou grandes variações nos resultados para todos os parâmetros, revelando a heterogeneidade do resíduo. Devido ao elevado tempo de permanência do lodo no tanque séptico (mais de dez anos), verificou-se baixa fração de STV, o que se mostrou benéfico para o desaguamento destes nos filtros. Os filtros apresentaram bom desempenho no processo de desaguamento do lodo, pois proporcionaram uma redução na umidade, passando de 98 para $76 \%$ no lodo acumulado no F1 e para $67 \%$ no lodo acumulado no F2. Com isso, houve um aumento no teor de ST do lodo acumulado, sendo que o F2 proporcionou um percentual maior (33\%), enquanto no F1 o percentual de sólidos foi de 24\%. Esses valores permitiram classificar os lodos acumulados como torta semissólida. Esse aumento no teor de sólidos do lodo acumulado no filtro indica a ocorrência do processo de desaguamento. Comparando os filtros, verifica-se que o F2, o qual recebeu a menor taxa de ST, apresentou maior concentração de sólidos no lodo acumulado, o que, por consequência, significa um melhor desaguamento. 
Em relação às remoções de matéria orgânica (representada pela DQO), os filtros também apresentaram bons resultados, com 99\% de eficiência para o F2 e 94\% para o F1. O F2, que recebeu a menor taxa de sólidos, apresentou melhor remoção de ST com concentração efluente de $472 \mathrm{mg} . \mathrm{L}^{-1}$ e remoção média de $96 \%$. O processo de desaguamento do lodo foi influenciado pelo processo de transpiração e evaporação das macrófitas, as quais permitiram uma maior perda de água do leito.

As análises estatísticas confirmaram que a utilização da taxa de ST de $125 \mathrm{kgST} . \mathrm{m}^{-2}$. nno $^{-1}$ (F2) permite um melhor desempenho em comparação ao filtro que teve a taxa de $250 \mathrm{kgST} . \mathrm{m}^{-2}$.ano ${ }^{-1}$ (F1).
Esta pesquisa demonstrou que os filtros plantados com macrófitas constituem uma alternativa tecnológica para tratamento do lodo de tanque séptico, pois os filtros proporcionam a redução do volume de água presente no lodo, permitem a sua mineralização e não requerem a remoção periódica do lodo acumulado. Com esses sistemas, é possível ainda diminuir os riscos associados ao manuseio do lodo. $\mathrm{O}$ produto final - lodo acumulado - poderá ser retirado após longos períodos de operação dos filtros (período que pode ser de 5 (cinco não deve ser por extenso?) a 30 anos, de acordo com o dimensionamento dos mesmos) e ser utilizado como fertilizante na agricultura ou condicionador do solo.

\section{Referências}

ANDREOLI, C.V.; VON SPERLING, M.; FERNANDES, F. Princípios do tratamento biológico de águas residuárias. Lodo de esgotos: tratamento e disposição final. Belo Horizonte: Departamento de Engenharia Sanitária e Ambiental; UFMG; Companhia de Saneamento do Paraná, 2001.

APHA, AWWA, WEF. Standard methods for the examination of water and wastewater1998. 20. ed. Washington: APHA, AWWA, WEF, 1998.

BRIX, H. Do macrophytes play a role in constructed treatment wetlands? Water Science Technology, v. 35, n. 5, p. 11-17, 1997.

COFIE, O.O. et al. Solid-liquid separation of faecal sludge using drying beds in Ghana: implications for nutrient recycling in urban agriculture. Water Research, v. 40, n. 1, p. 75-82, 2006.

COOPER, P.; WILLOUGHBY, N.; COOPER, D. The use of reed-beds for sludge drying. In: CIWEM/AquaEnviro Conference on Biossolids and Organic Residuals, $7^{\text {th }}$ ed. Wakefield, p. 85-89, 2004.

DE MAESENEER, J.L. Constructed wetlands for sludge dewatering. Water Science and Technology, v. 35, n. 5, p. 279-285, 1997.

HARDEJ, M.; OZIMEK, T. The effect of sewage sludge flooding on growth and morphometric parameters of Phragmites australis (Cav.) Trin. Ex Steudel. Ecol ogical Engineering, v. 18, p. 343-350, 2002.

HEINSS, U.; KOOTTATEP, T. Use of reed beds for faecal sludge dewatering. A synopsis of reviewed literature. Bangkok, Thailand: EAWAG - Swiss Federal Institute for Environmental Science \& Technology. SANDEC - Deptartmen for Water and Sanitation in Developing Countries, 1998.

Instituto Brasileiro de Geografia e Estatística (IBGE). Série estatística e série histórica. Disponível em: http://www.ibge.gov.br/series_estatisticas/ subtema.php?idsubtema=104. Acesso em: 17 nov. 2008.

KENGNE, I.M. et al. Effects of faecal sludge application on growth characteristics and chemical composition of Echinochloa pyramidalis
(Lam.) Hitch. and Chase and Cyperus papyrus L. Ecological Engineering, v. 34, n. 3, p. 233-242, 2008.

KIEHL, E.J. Fertilizantes orgânicos. São Paulo: Agronômica Ceres, 1985

KIM, B.J.; SMITH, E.D. Evaluation of sludge dewatering reed beds: a niche for small systems. Water Science and Technology.v. 35, n. 6, p. 21-28, 1997

KOOTTATEP, T. et al. Constructed wetlands for septage treatment towards effective faecal sludge management. In: CONFERENCE ON WETLANDS SYSTEMS FOR WATER POLLUTION CONTROL, 8, Arusha, Tanzania, 2002

METCALF \& EDDY. Wastewater engineering: treatment, disposal and reuse. 4. ed. Singapore: McGraw-Hill, 2004.

NIELSEN, S.; WILLOUGHBY, N. Sludge treatment and drying reed bed systems in Denmark. Water and Environmental Journal. v. 19, n. 4, p. 296-305, 2005.

NOUMSI, I.M. et al. Potencial of sludge drying beds vegetated with Cyperus papyrus L. and Echinochloa pyramidalis (LAM.) Hitchc \& Chase for faecal sludge treatment in tropical regions. In: INTERNATIONAL CONFERENCE ON WETLAND SYSTEMS FOR WATER POLLUTION CONTROL, 10, Lisboa, p. 943-953, 2006.

PAING, J.; VOISIN, J. Vertical flow constructed wetlands for municipal wastewater and septage treatment in French rural area. Water Science and Technology, v. 51, n. 9, p. 145-155, 2005.

PANUVATVANICH, A.; KOOTTATEP, T.; KONÉ, D. Influence of sand layer depth and percolate impounding regime on nitrogen transformation in vertical-flow constructed wetlands treating faecal sludge. Water Research, v. 43, n. 10, p. 2623-2630, 2009.

PHILIPPI, L.S. Funcionamento de fossas sépticas em condições reais: volume e acumulação de lodo. In: CONGRESSO BRASILEIRO DE 
ENGENHARIA SANITÁRIA E AMBIENTAL, 17, Natal. Anais... Natal: ABES, v. 2, tomo I, p. 633-642, 1993.

PLATZER, C. Design recommendations for subsurface flow constructed wetlands for nitrification and denitrification. Water Science Technology, v. 40, n. 3, p. 257-263, 1999

SEZERINO, P.H.; PHILIPPI, L.S. Tratamento de esgotos utilizando o potencial solo-planta. In: CONGRESSO INTERAMERICANO DE INGENIERIA SANITARIA Y AMBIENTAL, 26, CD-ROM. Anais. Lima, Peru: AIDIS, 1998.

SISTEMA NACIONAL DE INFORMAÇÕES SOBRE SANEAMENTO (SNIS). Diagnóstico dos serviços de água e esgotos - 2006. Brasília: Ministério das Cidades, 2007.
STEFANAKIS, A.I. et al. Surplus activated sludge dewatering in pilotscale sludge drying reed beds. Journal of Hazardous Materials, v. 172 p. $1122-1130,2009$

SUNTTI, C. Desaguamento de lodo de tanque séptico em filtros plantados com macrófitas. Dissertação (Mestrado em Engenharia Ambiental), Universidade Federal de Santa Catarina, Florianópolis, 2010.

UGGETTI, E. et al. Sludge dewatering and mineralization in two full-scale drying reed beds in Catalonia, Spain. Bioresourse Techonology, v. 100 p. 3882-3890, 2009

UGGETTI, E. et al. Sludge treatment wetlands: a review on the state of the art. Bioresourse Techonology, v. 101, n. 9, p. 2905-2912, 2010. 